\title{
Jogo Sério Ubíquo Integrado a Mundo Virtual OpenSim para o Ensino de Redes de Computadores (JASPION)
}

\author{
Aliane Loureiro Krassmann ${ }^{1}$, Roseclea Duarte Medina ${ }^{1}$ \\ ${ }^{1}$ Universidade Federal de Santa Maria (UFSM), Programa de Pós-Graduação em \\ Informática (PPGI) - - RS - Brasil \\ \{alkrassmann, roseclea.medina\}@gmail.com,
}

\section{Resumo}

O uso de jogos sérios digitais e a aprendizagem baseada em jogos têm contribuído para a expansão de novos paradigmas educacionais, onde o uso de recursos computacionais é incorporado ao modo tradicional de ensino. Aliado a estes avanços, os mundos virtuais 3D são cada vez mais utilizados como ferramentas para motivar o estudante, proporcionando imersão, autonomia e dinamicidade. Nesse sentido, este trabalho mostra o desenvolvimento e aplicação do JASPION, um Jogo Sério Ubíquo Integrado a Mundo Virtual OpenSim para o Ensino de Redes de Computadores. O jogo foi implementado na plataforma livre OpenSimulator valendo-se de scripts LSL e OSSL. Possui uma narrativa que mistura os estilos adventure, quest e quiz, em um enredo inspirado na série televisiva "O Fantástico Jaspion", que insere o jogador no papel de um personagem. Foram contemplados assuntos contidos na ementa da disciplina de Redes de Computadores do curso de graduação em Ciência da Computação. As características ubíquas foram proporcionadas pelo acesso pervasivo e a sensibilidade aos contextos de estilo cognitivo e de nível de expertise do estudante, possibilitando um perfil de jogabilidade personalizado e adequado a essas características. A adaptação ao estilo cognitivo do usuário ocorreu via materiais didáticos de apoio disponibilizados em cada fase. Já o nível de expertise foi adaptado por meio da dificuldade inicial do jogo, permitindo a evolução em três níveis. A abordagem buscou inserir o usuário em um contexto de aprendizagem transparente, refletindo aspectos da ubiquitous learning, e foi aplicada junto a um grupo de estudantes da área de Computação. Explorou-se um método de avaliação quali quantitativo híbrido embasado em dois instrumentos principais: questionário e análise dos dados de interação do usuário com o jogo. Fez-se um comparativo dos resultados obtidos levando-se em consideração o perfil da amostra. Os resultados mostram, entre outras contribuições, a existência de indícios motivacionais em estudantes sobre a disciplina de Redes de Computadores, destacando o potencial dessa abordagem na área educacional.

Referência (trabalho completo): Krassmann, A. L. Jogo Sério Ubíquo Integrado a Mundo Virtual OpenSim para o Ensino de Redes de Computadores (JASPION). Dissertação de Mestrado. Programa de Pós-Graduação em Informática (PPGI), Universidade Federal de Santa Maria (UFSM), 2016. 